\title{
The renin-angiotensin-aldosterone system in heart failure for the non-specialist: the past, the present and the future
}

\author{
Christopher Orsborne, ${ }^{1}$ Parminder S Chaggar, ${ }^{1,2}$ Steven M Shaw, ${ }^{1,2}$ \\ Simon G Williams ${ }^{1,2}$
}

${ }^{1}$ North West Heart Centre, University Hospital of South Manchester, Manchester, UK

${ }^{2}$ The University of Manchester, Manchester, UK

\section{Correspondence to} Dr Christopher Orsborne, University Hospital of South Manchester, Southmoor Road, Wythenshawe, Manchester M23 9LT, UK; Chris.orsborne@ doctors.net.uk

Received 17 February 2016 Revised 1 August 2016 Accepted 27 August 2016 Published Online First 26 September 2016
CrossMark

To cite: Orsborne C Chaggar PS, Shaw SM, et al. Postgrad Med J

2017;93:29-37

\section{ABSTRACT}

Heart failure is one of the major public health challenges facing the Western world. Its prevalence is increasing as the population ages and modern techniques are implemented to manage cardiac disease. In response, there has been a sustained effort to develop novel strategies to address the high levels of associated morbidity and mortality. Indeed, agents that target the renin-angiotensin-aldosterone system (RAAS) have transformed the way in which we manage heart failure. Despite this, mortality in heart failure is poorer than in many malignancies and a large burden of morbidity and recurrent hospitalisation remains. Here, we review the role of RAAS modulation within the field of systolic heart failure. In particular, we provide practical guidance on using current RAAS blockade agents and focus on the recent emergence of new agents that promise additional substantial benefit to those living with left ventricular systolic dysfunction.

\section{INTRODUCTION}

Heart failure is increasingly prevalent in the Western world, affecting 1\%-2\% of the total population. It is more common in the elderly, where prevalence is as high as $10 \%$ in those aged over 70 years. ${ }^{1}$ Despite advances in treatment, heart failure is associated with a poor prognosis, which is worse than many common malignancies, high rates of acute hospital admissions and severely impaired quality of life. ${ }^{2}{ }^{3}$ However, epidemiological studies suggest that mortality and hospitalisation rates in heart failure are slowly improving because of modern medical and device therapies. ${ }^{3-5}$ In particular, the impact of treatments that target the renin-angiotensin-aldosterone system (RAAS), which underpins the neurohormonal pathogenesis of heart failure, has been significant. $\beta$-Blockers $(\mathrm{BBs})$, angiotensin-converting enzyme (ACE) inhibitors, angiotensin receptor blockers (ARBs) and mineralocorticoid receptor antagonists (MRA) have quickly been adopted into international guidelines because of substantial evidence of morbidity and mortality benefit provided by large, multicentre randomised controlled trials (RCTs). ${ }^{6}$ A new class of drug to treat heart failure has been awaited for over 15 years during which progress has largely been made through refining existing treatment strategies and the advent of device therapies. However, the recent PARADIGM-HF trial offers a promising novel treatment in the form of an angiotensin receptor and neprilysin inhibitor (ARNI), sacubitril-valsartan, a new class of RAAS blockade. ${ }^{7}$
In order to appreciate the position of this novel agent it is necessary to understand the impact that RAAS modulation has already had in the field of systolic heart failure and the challenges that remains. Here, we discuss the historical and contemporary role of RAAS modulation in order to contextualise the significance of new agents.

\section{THE NEUROHORMONAL BASIS OF HEART FAILURE}

The RAAS is a central feature in the pathophysiology of heart failure. Adaptations in this system occur in response to an inability to meet the demands of vital organ systems. The RAAS is activated by renal hypoperfusion and sympathetic activation. The key product of this cascade is angiotensin II (ATII), which has multiple systemwide effects that are initially compensatory but subsequently exacerbate the heart failure syndrome. An overview of the role of the RAAS in heart failure is outlined in figure 1. The sympathetic nervous system (SNS) is also intrinsic to the neuroendocrine pathophysiology of heart failure and is closely interlinked with the RAAS. Initially, catecholamine excess temporarily increases cardiac output via inotropic and chronotropic effects but subsequently exacerbate myocardial ischaemia, hypertrophy and arrhythmia. ${ }^{8}$ Counterregulatory mediators, the best understood of which are the natriuretic peptides (NPs), oppose the RAAS and SNS. A-type natriuretic peptide and B-type natriuretic peptide (BNP) are secreted in response to myocardial wall stretch, promoting vasodilatation and natriuresis and inhibit the SNS and RAAS. These peptides are partly degraded by neprilysin, the enzyme that is central to a new class of prognostically significant therapy for heart failure. 7 In summary, although RAAS and SNS adaptations initially improve cardiac output, they progressively overwhelm the opposing vasodilator and natriuretic mediators and propagate the heart failure syndrome (figure 2). This review discusses the foundations of modern antiheart failure treatment, more recent developments and the future of RAAS modulation in heart failure. The key studies are summarised in table 1.

\section{THE PAST}

\section{Angiotensin-converting enzyme inhibitors}

ACE inhibitors are notable as the first class of drug to demonstrate significant mortality benefit in the landmark trials, CONSENSUS and SOLVD. CONSENSUS, a double-blind RCT, compares 




Figure 1 Schematic overview of the renin-angiotensin-aldosterone system and its manifestations in heart failure as well as the mechanism of action of currently recommended pharmacological agents. ADH, antidiuretic hormone; ACE-i, angiotensin-converting enzyme inhibitor; ARB, angiotensin receptor blocker; MRA, mineralocorticoid receptor antagonists; $B B$, $\beta$-blocker.

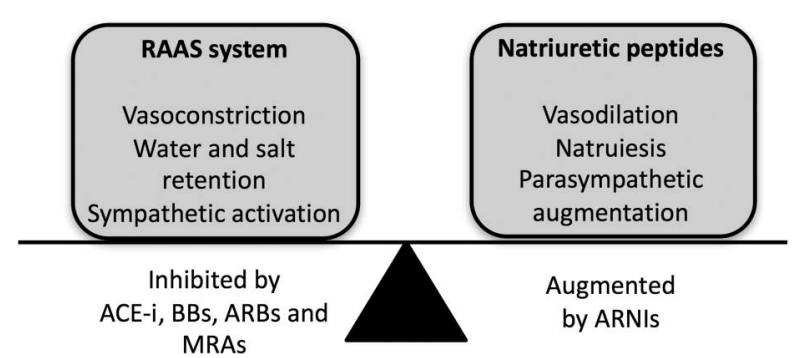

Figure 2 Schematic of the interaction between the renin-angiotensin-aldosterone system (RAAS) system and the natriuretic peptides and how the RAAS modulators and angiotensin receptor neprilysin inhibitors (ARNIs) influence the balance. ACE-i, angiotensin-converting enzyme inhibitor; $A R B$, angiotensin receptor blocker; MRA, mineralocorticoid receptor antagonists; $B B$, $\beta$-blocker.

enalapril with placebo in patients with New York Heart Association (NYHA) class IV heart failure symptoms and an ejection fraction $(\mathrm{EF})<35 \%$. At randomisation, patients were established on diuretics and digoxin, in addition to spironolactone in $52.5 \%$. In an incredibly sick study population with 1 -year mortality of $52 \%$ in the placebo arm, enalapril reduced all-cause mortality by $31 \%$ (relative risk $=0.69, \mathrm{p}=0.001$ ). CONSENSUS was the first to demonstrate a significant all-cause mortality benefit in heart failure and following this success, SOLVD treatment goes on to examine the role of enalapril in a much larger and critically, less symptomatic cohort. Here, $>85 \%$ of those included were in NYHA class II or III and active treatment was associated with a significant risk reduction in allcause mortality of $16 \%$ (risk reduction $16 \% 0.84,95 \%$ CI $5 \%$ to $26 \%, \mathrm{p}<0.0036$ ) and a $26 \%$ lower risk of heart failure-related hospital admissions or death (relative risk 0.74 $95 \%$ CI $34 \%$ to $18 \%, \mathrm{p}<0.0001)$. These studies demonstrate similar overall withdrawal rates in the active treatment and placebo groups, although hypotension, dizziness and cough are identified as side effects of ACE inhibitor therapy. ${ }^{9} 10$

ACE inhibitors were clearly beneficial in moderate-to-severe symptomatic heart failure but the SOLVD investigators go on to assess ACE inhibitor efficacy in patients with minimal symptoms despite $\mathrm{EF}<35 \%$. The SOLVD-Prevention study recruited patients with minimally symptomatic heart failure (NYHA class I-II), and not based on any antiheart failure medications. Even in the absence of significant symptoms, enalapril demonstrates a $20 \%$ reduction in the combined outcome of heart failure mortality or heart failure hospitalisation (95\% CI $9 \%$ to $30 \%$, $\mathrm{p}<0.001)$. $^{11}$

The early ACE inhibitors studies mostly include patients with a background of ischaemic heart disease and several studies have examined the role of ACE inhibitors specifically in the postmyocardial infarction (MI) heart failure population. Three large well-designed RCTs, Survival and Ventricular Enlargement (SAVE), Trandolapril Cardiac Evaluation (TRACE) and Acute Infarction Ramipril Efficacy examine the role of ACE inhibitors post-MI (AIRE); each using a different ACE inhibitor (captopril, trandolopril and ramipril, respectively). ${ }^{12-14} \mathrm{~A}$ methodically sound systematic review of the three trials demonstrated that in the 5966 study patients, all-cause mortality decreased from 
Table 1 A summary of the key randomised controlled trials of RAAS modulating drugs in the field of heart failure

\begin{tabular}{|c|c|c|c|c|c|}
\hline & Study & Treatment & Control & Key inclusion criteria & Key findings \\
\hline 1987 & CONSENSUS & Enalapril & Placebo & $\mathrm{EF}<35 \%$, NYHA class IV & $\begin{array}{l}\text { A significant reduction in all-cause mortality and cardiac mortality, } \\
\text { significant decrease in NYHA class }\end{array}$ \\
\hline 1991 & SOLVD-T & Enalapril & Placebo & $\begin{array}{l}\text { EF }<35 \%, \sim 90 \% \text { NYHA class } \\
\text { II-III }\end{array}$ & $\begin{array}{l}\text { A significant reduction in all-cause mortality with a significant } \\
\text { reduction in a combined outcome of death or hospitalisation }\end{array}$ \\
\hline 1992 & SOLVD-P & Enalapril & Placebo & $\begin{array}{l}\mathrm{EF}<35 \% \text {, NYHA class I-II, not } \\
\text { on any medications for heart } \\
\text { failure }\end{array}$ & $\begin{array}{l}\text { A significant reduction in the combined outcome of all-cause } \\
\text { mortality or heart failure hospitalisation }\end{array}$ \\
\hline 1999 & CIBIS II & Bisoprolol & Placebo & $\mathrm{EF}<35 \%$, NYHA class III-IV & $\begin{array}{l}\text { Significant reduction in all-cause mortality, significantly fewer } \\
\text { sudden cardiac deaths }\end{array}$ \\
\hline 1999 & RALES & Spironolactone & Placebo & $\begin{array}{l}\mathrm{EF}<35 \% \text {, NYHA class III-IV, } \\
\text { on an ACE inhibitors }\end{array}$ & $\begin{array}{l}\text { Significant reduction in cardiovascular and all-cause mortality as well } \\
\text { as hospitalisation and NYHA class. Significantly more } \\
\text { gynaecomastia, no significant increase in the occurrence of serious } \\
\text { hyperkalaemia }\end{array}$ \\
\hline 2000 & MERIT-HF & Metoprolol & Placebo & $\mathrm{EF}<40 \%$, NYHA class II-IV & $\begin{array}{l}\text { Significant decrease in all-cause mortality, sudden deaths and deaths } \\
\text { from worsening heart failure }\end{array}$ \\
\hline 2001 & VALHEFT & $\begin{array}{l}\text { Valsartan and ACE } \\
\text { inhibitors }\end{array}$ & Placebo & $\begin{array}{l}\mathrm{EF}<40 \% \text {, NYHA class II-IV, } \\
>92 \% \text { also on an ACE } \\
\text { inhibitor }\end{array}$ & $\begin{array}{l}\text { Significant decrease in cardiovascular hospitalisation, no significant } \\
\text { decrease in all-cause or cardiovascular mortality }\end{array}$ \\
\hline 2002 & COPERNICUS & Carvedilol & Placebo & $\begin{array}{l}\mathrm{EF}<25 \% \text {, symptoms of heart } \\
\text { failure at rest or on minimal } \\
\text { exertion }\end{array}$ & $\begin{array}{l}\text { Significantly reduced the rate of death and hospitalisation, patients } \\
\text { reported feeling better via a patient global assessment }\end{array}$ \\
\hline 2003 & CHARM-ADDED & $\begin{array}{l}\text { Candesartan and ACE } \\
\text { inhibitors }\end{array}$ & Placebo & $\begin{array}{l}\mathrm{EF}<35 \% \text {, NYHA class II-IV, } \\
>98.8 \% \text { on an ACE inhibitor }\end{array}$ & $\begin{array}{l}\text { Significant reduction in a combined outcome of heart failure } \\
\text { admission and cardiovascular death, no significant decrease in } \\
\text { all-cause mortality of cardiovascular mortality }\end{array}$ \\
\hline 2003 & CHARM-ALTERNATIVE & Candesartan & Placebo & $\begin{array}{l}\mathrm{EF}<40 \% \text {, NYHA class II-IV, } \\
\text { intolerant to ACE inhibitors }\end{array}$ & $\begin{array}{l}\text { Significant reduction in cardiovascular death or hospital admission, } \\
\text { significant reduction in heart failure hospitalisation and } \\
\text { cardiovascular mortality. No significant reduction in all-cause } \\
\text { mortality }\end{array}$ \\
\hline 2003 & EPHESUS & Eplerenone & Placebo & $\begin{array}{l}\mathrm{EF}<40 \% \text {, patients post-MI } \\
\text { with signs of heart failure or } \\
\text { diabetes }\end{array}$ & $\begin{array}{l}\text { Significant reduction in cardiovascular and all-cause mortality as well } \\
\text { as hospitalisation. Significantly more hyperkalaemia but less } \\
\text { hypokalaemia }\end{array}$ \\
\hline 2011 & EMPHASIS-HF & Eplerenone & Placebo & $\mathrm{EF}<35 \%$, NYHA class II & $\begin{array}{l}\text { Stopped early after } 21 \text { months. Significant reduction in } \\
\text { cardiovascular and all-cause mortality as well as hospitalisation. } \\
\text { Significantly more hyperkalaemia }\end{array}$ \\
\hline 2014 & PARADIGM-HF & Sacubitril-valsartan & Enalapril & $\mathrm{EF}<35 \%$, NYHA class II-IV & $\begin{array}{l}\text { Significant reduction in all-cause mortality, significant reduction in } \\
\text { combined cardiovascular deaths or first hospitalisation. No } \\
\text { significant increase in angiooedema }\end{array}$ \\
\hline
\end{tabular}

EF, ejection fraction; MI, myocardial infarction; NYHA, New York Heart Association; RAAS, renin-angiotensin-aldosterone system.

$29.1 \%$ to $23.4 \%$ (OR $0.74,95 \%$ CI 66 to $83, \mathrm{p}<0.0001$ ), hospitalisation from $15.5 \%$ to $11.9 \%$ (OR $0.73,95 \%$ CI 0.63 to $0.85, \mathrm{p}<0.0001)$ and re-infarction from $13.2 \%$ to $10.8 \%$ (OR $0.8,95 \%$ CI 0.69 to $0.94, \mathrm{p}=0.0057$ ) over a 31 -month follow-up period. ${ }^{15}$

Maximal dose titration is a key feature of all of the RCTs of heart failure therapies and is recommended in all international guidelines for clinical practice. ${ }^{6}$ ATLAS, an RCT examining the effects of ACE inhibitor dosage, demonstrates significant benefits from high-dose as opposed to low-dose lisinopril. Compared with low-dose therapy, high-dose treatment (mean doses $4.5 \mathrm{mg}$ $\pm 1.1 \mathrm{mg}$ vs $33.2 \mathrm{mg} \pm 5.4 \mathrm{mg}$ ) demonstrates an $8 \%$ reduction in all-cause mortality (HR $0.92,95 \%$ CI 0.82 to $1.03, \mathrm{p}=0.128$ ) and a significant $12 \%$ reduction in the combined outcome of death and hospitalisation (HR 0.88 , 95\% CI 0.82 to 0.96 , $\mathrm{p}=0.002)$. Crucially, there is no significant increase in withdrawals from study with high-dose treatment indicating an acceptable side-effect profile at fully optimised doses. ${ }^{16}$

In summary, ACE inhibition is associated with significant reductions in mortality, morbidity and hospitalisation for heart failure with an acceptable side-effect profile. This effect is applicable to those with, and without, symptoms and crucially, is most pronounced at the highest tolerated dose. ACE inhibition therefore carries a class I, level A recommendation, in international guidelines as first-line treatment in patients with $\mathrm{EF}<40 \%$ (figure 3). ${ }^{6}$ Table 2 provides practical guidance for clinicians using ACE inhibitors in heart failure.

\section{Spironolactone}

With the role of ACE inhibitors established, there was an initial assumption among clinicians that the use of MRAs in addition to ACE inhibitors would be likely to precipitate renal complications. ${ }^{19}$ However, the role of spironolactone as an 'add-on' treatment to ACE inhibitors in heart failure was established in the RALES trial; a double-blind RCT including patients with NYHA class III or IV heart failure, already treated with ACE inhibitors and with $\mathrm{EF}<35 \%$. Spironolactone reduced the risk of death from any cause by 30\% (relative risk $0.7,95 \%$ CI 0.6 to $0.82, \mathrm{p}<0.001$ ) and hospitalisation due to worsening heart failure by $35 \%$ (relative risk $0.65,95 \%$ CI 54 to $77, \mathrm{p}<0.001$ ), while NYHA symptom class also improved. Only 14/822 patients $(2 \%)$ in the spironolactone arm compared with $10 / 841$ (1\%) in the placebo arm had serious adverse events involving hyperkalaemia $(p=0.42)$. As anticipated there was a significant increase in the number of men complaining of breast symptoms with spironolactone $(1 \%$ vs $10 \%, p<0.001)$, but overall, adverse event rate was equivalent to placebo $(p=0.17)$. The trial 

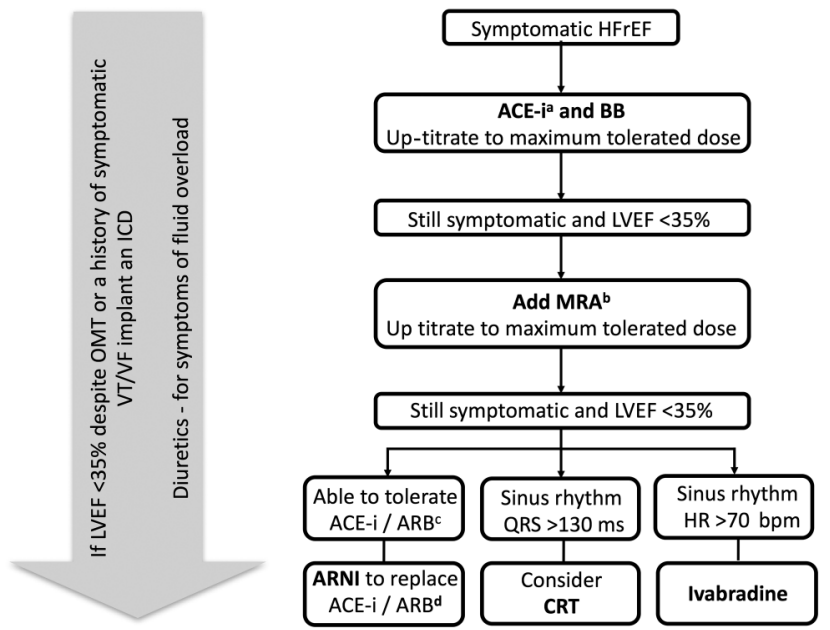

Figure 3 Flow diagram of the recommended pharmacological management of heart failure adapted from the European Society of Cardiology guidelines 2016. The term symptomatic refers to New York Heart Association class II-IV, if asymptomatic consider reducing furosemide dose. CRT, ivabradine and ARNIs should be used in combination when appropriate. If despite the above persistent symptoms remain, digoxin, hydralazine and isosorbide dinitrate, left ventricular assist devices and heart transplantation can be considered by a specialist. HFrEF, heart failure with reduced ejection fraction; $A C E-i$, angiotensin-converting enzyme inhibitor; $B B, \beta$-blocker; MRA, mineralocorticoid receptor antagonist; $A R N I$, angiotensin receptor neprilysin inhibitor; CRT, cardiac resynchronisation therapy; ICD, implantable cardiac defibrillator; VT, ventricular tachycardia; VF, ventricular fibrillation; OMT, optimal medical therapy. ${ }^{a}$ Use angiotensin receptor blocker (ARB) instead of ACE-i when intolerant/ contraindicated. ' Use ARB instead of MRA when intolerant/ contraindicated. 'At doses equivalent to enalapril $10 \mathrm{mg}$ twice daily. ${ }^{\mathrm{d}}$ Only if B-type natriuretic peptides (BNP) $\geq 150 \mathrm{pg} / \mathrm{mL}$ or plasma $\mathrm{N}$-terminal pro-brain natriuretic peptide (NT-proBNP) $\geq 600 \mathrm{pg} / \mathrm{mL}$, unless there has been a heart failure-related admission in the previous 12 months, when the cut-offs are BNP $\geq 100 \mathrm{pg} / \mathrm{mL}$ or NT-proBNP $\geq 400 \mathrm{pg} / \mathrm{mL}^{35}$ was discontinued early after 24 months following significant benefit at interim analysis. ${ }^{19}$

Spironolactone inferred a substantial benefit in addition to the benefits gained with optimised ACE inhibition with an acceptable safety profile of dual RAAS blockade. Further studies elucidating the role of modern MRAs in heart failure are discussed later.

\section{B-Blockers}

COPERNICUS, MERIT-HF and CIBIS II are the three key RCTs examining the role of BBs in heart failure. CIBIS II examined the effects of bisoprolol in severely symptomatic heart failure. A total of 2647 NYHA class III-IV patients with $\mathrm{EF}<35 \%$ were randomised to bisoprolol or placebo. After a mean follow-up of 1.3 years, the trial was stopped early due to significant mortality benefit at interim analysis. All-cause mortality significantly reduced by $34 \%$ (HR 0.66 , 95\% CI 0.54 to $0.81, \mathrm{p}<0.0001)$ and hospitalisation by $20 \%$ (HR $0.80,95 \% \mathrm{CI}$ 0.71 to $0.91, \mathrm{p}=0.0006$ ). There was no significant increase in treatment withdrawal compared with the placebo arm $(p=0.98) .{ }^{20}$ MERIT-HF examines the role of BB in a less symptomatic cohort, randomising 3991 patients with an $\mathrm{EF}<40 \%$ and in NYHA class II-IV to metoprolol or placebo. All-cause mortality reduced by $34 \%$ (relative risk $0.66,95 \%$ CI 0.53 to $0.81, \mathrm{p}<0.0001)$ at interim analysis, prompting early study termination after just 1 year as a result. ${ }^{21}$ Finally, COPERNICUS examined both morbidity and mortality. A total of 2289 patients with symptoms of heart failure at rest or on minimal exertion and an $\mathrm{EF}<25 \%$ were followed up for an average of 10.4 months. Carvedilol reduced the combined risk of death from any cause or hospitalisation for a cardiovascular reason by $27 \%(\mathrm{p}=0.00002)$ and reduced the combined risk of hospitalisation or death by $31 \%(\mathrm{p}=0.000004) .^{22}$

$\mathrm{BBs}$ reduce all-cause mortality, hospitalisation and morbidity in mild-to-severe symptomatic heart failure. Of note, $>90 \%$ of patients in the three studies were established on ACE inhibitors and the effects are in addition to the $\sim 30 \%$ mortality benefit of ACE inhibition. Furthermore, benefit is seen within 12 months

Table 2 Guidance on when, where and how to use ACE inhibitors and ARBs in heart failure and guidance on 'troubleshooting' common issues

\begin{tabular}{|c|c|}
\hline When to use & $\begin{array}{l}\text { ACE inhibitors are the first-line treatment in all patients with systolic heart failure alongside } \beta \text {-blockers. ARBs can be used instead of ACE inhibitors in } \\
\text { those that have a definite proven intolerance of an ACE inhibitor. }\end{array}$ \\
\hline Contraindications & Renal artery stenosis, history of angiooedema. \\
\hline Caution & $\begin{array}{l}\text { Aortic stenosis, potassium }>5.0 \mathrm{mmol} / \mathrm{L} \text {, creatinine }>221 \mu \mathrm{mol} / \mathrm{L} \text {, symptomatic or severe hypotension (be aware of first dose hypotension), other drugs } \\
\text { (NSAIDs, other nephrotoxic drugs). }\end{array}$ \\
\hline How to use & $\begin{array}{l}\text { 'Start low and go slow'. Double the dose every } 2 \text { weeks at the fastest. Monitor blood pressure and blood biochemistry 1-2 weeks after initiation and } \\
\text { final dose titration. }\end{array}$ \\
\hline Counselling & Explain expected benefits and possible side effects, advise on monitoring and drugs to avoid. Liaise with community heart failure nurse-led services. \\
\hline Troubleshooting & $\begin{array}{l}\text { Hypotension } \\
\text { If asymptomatic, no action is usually required. If symptomatic, consider reducing the dose of other medications, for example, diuretics or other } \\
\text { antihypertensive drugs that do not offer prognostic benefit in heart failure such as calcium channel blockers. } \\
\text { Cough } \\
\text { Initially seek alternative cause. Many patients with heart failure will smoke and many will have a degree of pulmonary oedema either of which can cause } \\
\text { a cough. A severe cough might warrant the withdrawal of an ACE inhibitor. This should be proven where possible by withdrawal and re-initiation. } \\
\text { Replace with an ARB only if intolerant, they are not interchangeable in terms of prognostic benefit. } \\
\text { Worsening renal function } \\
\text { A } 50 \% \text { increase in creatinine above baseline or up to } 266 \mu \text { mol/L or a } K^{+}<5.5 \mathrm{mmol} / \mathrm{L} \text { does not usually require a change in dose. } \\
\text { If changes exceed these parameters, consider stopping other nephrotoxic medication including if possible diuretics. If this does not help or is not } \\
\text { possible, the ACE inhibitor or ARBs dose can be halved and bloods can be rechecked in } 1-2 \text { weeks. } \\
\text { If creatinine more than doubles, the creatinine peaks above } 310 \mu \text { mol/L or the potassium rises to }>5.5 \mathrm{mmol} \text {, the ACE inhibitor or ARB should be stopped } \\
\text { immediately and specialist advice sought. } \\
\text { Renal function should be monitored serially until parameters reach a plateau. }\end{array}$ \\
\hline
\end{tabular}


Table 3 Guidance on when, where and how to use BBs in heart failure and guidance on 'troubleshooting' common issues

\begin{tabular}{|c|c|}
\hline When to use & ACE inhibitors are the first-line treatment in all patients with systolic heart failure alongside BBs. \\
\hline When not to use & Asthma, marked bradycardia, pheochromocytoma. \\
\hline Cautions & $\begin{array}{l}\text { Current or recent exacerbation of heart failure, severe heart failure (NYHA class III-IV). Bradycardia, hypotension (<90 mm Hg systolic), signs of } \\
\text { current volume overload. Psoriasis, hypoglycaemia, concurrent use of rate-limiting calcium channel blockers. }\end{array}$ \\
\hline How to use & $\begin{array}{l}\text { 'Start low and go slow'. Double the dose every } 2 \text { weeks at the fastest. Monitor blood pressure and blood biochemistry 1-2 weeks after initiation and } \\
\text { final dose titration. Monitor heart rate and blood pressure and watch for signs of decompensating heart failure. }\end{array}$ \\
\hline Counselling & $\begin{array}{l}\text { Explain expected benefits and possible side effects, advise on monitoring and drugs to avoid. Explain intended benefits may not occur for months } \\
\text { and that stopping their BB should be done only with medical supervision. Liaise with community heart failure nurse-led services. }\end{array}$ \\
\hline Troubleshooting & $\begin{array}{l}\text { If increasing congestion increase dose of diuretic and/or halve dose of BB if increasing the diuretic does not work. In fatigue (and/or bradycardia) } \\
\text { halve dose of BB and review patient in 1-2 weeks. If serious deterioration, stop the BB and seek specialist advice. } \\
\text { Bradycardia } \\
\text { If heart rate }<50 \mathrm{bpm} \text { and worsening symptoms halve the dose of the BB or, if there is a severe deterioration, stop the BB (rarely necessary) and } \\
\text { review need for other drugs. Arrange an ECG to exclude heart block and seek specialist advice. } \\
\text { Hypotension } \\
\text { Asymptomatic hypotension does not usually require any changes but if symptomatic hypotension occurs, consider stopping/reducing other } \\
\text { hypotensive agents (diuretics, calcium channel blockers). If these measures do not solve problem, seek specialist advice. }\end{array}$ \\
\hline
\end{tabular}

of treatment and in all studies BBs are well tolerated. Practical guidance on the use of $\mathrm{BB}$ in heart failure is available in table 3.

\section{Angiotensin receptor blockers}

Although the concept of ACE inhibition was proven in heart failure, basic science studies demonstrated that ATII could be produced independently of ACE. It was therefore logical to pursue more selective receptor blockade using ARBs. ${ }^{23}{ }^{24}$ The key questions for clinicians are first, whether an ACE and ARB in combination is more effective and as safe as ACE inhibition alone and second whether ARBs could be used instead of ACE inhibitors in those who encounter intolerable side effects.

\section{ARB and ACE (added)}

VALHEFT and CHARM-added are the two most influential studies that examine the ACE inhibitor and ARB combination. Both are randomised, double-blind RCTs that compare the combination of an ACE inhibitor and an ARB versus the combination of an ACE inhibitor and placebo.

VALHEFT randomised 5010 patients with NYHA class II-IV heart failure and an $\mathrm{EF}<40 \%$. After 23 months follow-up, there was no significant decrease in all-cause mortality, cardiovascular mortality or hospitalisation rates. Similarly, in CHARM-added which also included NYHA class II-IV patients with an $\mathrm{EF}<40 \%$, there was no significant all-cause mortality benefit (HR $0.89,95 \%$ CI 0.77 to $1.02, p=0.086$ ) despite a significant reduction in the combined end point of heart failure admissions and cardiovascular death (HR $0.85,95 \%$ CI 0.75 to 0.96 , $\mathrm{p}=0.01)$. The safety profile of combination therapy is also concerning with excess adverse events leading to discontinuation of the study drug in the ARB-arm of both trials, mainly due to dizziness, hypotension, hyperkalaemia and renal impairment. Of particular concern, severe hyperkalaemia defined as serum potassium of $>6 \mathrm{mmol} / \mathrm{L}$ occurred in $3 \%$ of patients in comparison to $1 \%$ in the placebo arm $(\mathrm{p}<0.0001){ }^{25} 26$

\section{ARB instead of ACE}

CHARM-alternative examines the role of ARBs in patients with NYHA class II-IV heart failure and $\mathrm{EF}<40 \%$ by selectively recruiting those who could not tolerate an ACE inhibitor, mainly due to cough, hypotension or renal dysfunction. A total of 2028 patients were recruited for 33 months and were treated with either $\mathrm{ARB}$ or placebo in a double-blind fashion. The combined outcome of heart failure hospitalisation or cardiovascular death significantly reduced with an adjusted HR of 0.70 (95\% CI 0.60 to $0.81, \mathrm{p}<0.0001)$. However, there was no significant decrease in all-cause mortality and the incidence of ARB discontinuation was significantly higher than the placebo group (3.7\% ARB vs $0.9 \%$ placebo, $\mathrm{p}<0.0001)$ due to hypotension, renal dysfunction and hyperkalaemia. ${ }^{27}$ Therefore, ACE inhibitors retain their position as the first-line RAAS blockade agent of choice in heart failure and ARBs should only be prescribed if there are definitive side effects directly attributable to ACE inhibitors. In the case of ACE inhibitor cough, since cough is a common and non-specific symptom, it is recommended a direct causal link with the ACE inhibitor be established with a re-challenge before changing to an ARB.

If $A R B s$ are used in clinical practice dose up-titration is essential. The HEAAL study compares high-dose and low-dose losar$\tan (50 \mathrm{vs} 150 \mathrm{mg})$ in a randomised fashion and demonstrated a reduction in all-cause mortality of $6 \%$ (HR 0.94, 95\% CI 0.84 to $1.04, \mathrm{p}=0.24)$ and a reduction in heart failure-related hospital admissions of $13 \%$ (HR $0.87,0.76-0.98, \mathrm{p}=0.025$ ) with high-dose therapy. Withdrawal from the study in both treatment arms was comparable despite the higher dose. ${ }^{28}$

Overall, the combination of an ACE inhibitor and ARB reduces the risk of hospitalisation, but is not associated with allcause mortality benefit and confers a significant side-effect profile in comparison to ACE inhibition alone. ARB treatment in those that are truly intolerant of ACE inhibitors is an acceptable strategy, on the basis that ARBs reduce heart failure hospitalisation compared with placebo in this select population. Clearly, ACE inhibitors and ARBs are not interchangeable in this context and have distinct roles in clinical practice. ARBs are strictly reserved for patients with definite ACE inhibitor side effects. Indeed, if a patient develops heart failure while established on an ARB for another indication, switching to an ACE inhibitor should be considered if it has not been tried previously. Practical guidance on the use of ARBs is summarised in table 2 .

\section{THE PRESENT}

Recent advances in RAAS blockade in heart failure have focused on the role of eplerenone. The RALES trial demonstrated the efficacy of MRAs in severely symptomatic heart failure and the EMPHASIS-HF trial goes on to examine the role of eplerenone 
Table 4 Guidance on when, where and how to use MRAs in heart failure and guidance on 'troubleshooting' common issues

As a third agent in those already on maximal tolerated dose of ACE inhibitors and a $\beta$-blocker in all patients with systolic heart failure NYHA class II-IV.

When not to use

Cautions

How to use

Counselling

Troubleshooting
Significant renal dysfunction creatinine $>221 \mu \mathrm{mol} / \mathrm{L}$ or significant hyperkalaemia $\mathrm{K}^{+}>5.0 \mathrm{mmol} / \mathrm{L}$. Drug interactions such as NSAIDs, other nephrotoxic drugs and low-salt preparations containing a high potassium load.

'Start low and go slow'. Check blood chemistry at 1, 4, 8 and 12 weeks; 6, 9 and 12 months, 6 monthly thereafter.

Explain expected benefits, symptom improvement occurs in weeks to months. Advise on the use of over-the-counter medications (NSAIDs). Temporarily stop spironolactone and contact your doctor if diarrhoea and/or vomiting develop.

Hyperkalaemia and renal dysfunction

If $\mathrm{K}^{+}$rises between 5.5 and $6.0 \mathrm{mmol} / \mathrm{L}$ or creatinine rises to $>221 \mu \mathrm{mol} / \mathrm{L}$, reduce dose and monitor blood chemistry closely.

If $\mathrm{K}^{+}$rises to $>6.0 \mathrm{mmol} / \mathrm{L}$ or creatinine to $>354 \mu \mathrm{mol} / \mathrm{L}$, stop the drug and seek specialist advice.

Adapted from McMurray et al and the British National Formulary. ${ }^{17} 18$

MRA, mineralocorticoid receptor antagonists; NSAIDs, non-steroidal anti-inflammatory drugs; NYHA, New York Heart Association.

in patients with heart failure and mild symptoms. Patients with NYHA class II symptoms, an $\mathrm{EF}<35 \%$ and a recent heart failure-related hospitalisation or elevated BNP were randomised to eplerenone or placebo. The trial was stopped early after 21 months as it demonstrated significant benefit on the combined end point of cardiovascular death or first heart failure hospitalisation (HR 0.63, 95\% CI 0.54 to $0.74, \mathrm{p}<0.001$ ). Significant reductions were also demonstrated in secondary end points of all-cause mortality (HR $0.76,95 \%$ CI 0.62 to 0.93 , $\mathrm{p}=0.008$ ) and cardiovascular mortality (HR $0.76,95 \%$ CI 0.62 to $0.93, p=0.01)$. Furthermore, the role of eplerenone post-MI has been established in the EPHESUS study, a large multicentre RCT. Patients with an $\mathrm{EF}<40 \%$ and clinical features of heart failure or diabetes were randomised 3-14 days post-MI to eplerenone or placebo. Both all-cause mortality (relative risk $=0.85$, $95 \%$ CI 0.75 to $0.96, p=0.008$ ) and the combined end point of death from any cause or cardiac hospitalisation were significantly reduced (relative risk $=0.87,95 \%$ CI 0.79 to 0.95 , $\mathrm{p}=0.002$ ). Eplerenone increases serum creatinine and potassium levels in both trials; however, there are no serious adverse events secondary to hyperkalaemia in either trial and the rate of serious hypokalaemia was significantly reduced. Unlike spironolactone, there is no increase in breast symptoms compared with placebo. Interestingly in EPHESUS, the adverse event rate was higher in the placebo arm including one death attributed to hyperkalaemia. Patients in both trials were already benefitting from maximally tolerated doses of BBs and ACE inhibitors or ARBs so the positive effects of eplerenone are seen in addition to optimised baseline therapy. ${ }^{29} 30$ Guidance on the use of MRAs in clinical practice is available in table 4.

\section{THE FUTURE}

\section{Angiotensin receptor and neprilysin inhibitors}

Thus far, there has been an emphasis on inhibition of the RAAS. However, the pathology of heart failure is an imbalance between regulatory and counterregulatory mechanisms (figure 2). The best-characterised mediators opposing the deleterious effects of RAAS activation in heart failure are the NPs. Therefore, inhibitors of neprilysin, an enzyme that degrades NPs have been used in novel treatments for heart failure.

Initial trials of an ACE inhibitor and a neprilysin inhibitor combination, omapatrilat, in heart failure and hypertension cohorts were unsuccessful due to an unacceptably high incidence of angiooedema. This relates to excess bradykinin accumulation since both ACE and neprilysin inhibition block the bradykinin degradation pathway. ${ }^{31-34}$ However, since ARBs do to not increase bradykinins, combination with an ARB has recently been studied in the PARDIGM-HF trial.
PARDIGM-HF recruited patients with an EF $<40 \%$ and NYHA class II-IV heart failure and elevated BNP despite optimal antiheart failure therapy and randomised them to enalapril or the ARNI, sacubitril-valsartan. The study featured a novel 'run-in' period where patients received both treatments in turn for a short period to ensure that patients could tolerate both drugs at the required doses prior to randomisation. Ninety-three per cent of patients were established on BB therapy, $55.6 \%$ on MRAs and 7\% had received cardiac resynchronisation therapy.

The primary outcomes of the study were all significantly reduced in the ARNI arm with reduction in death from cardiovascular causes or first heart failure hospitalisation from $26.5 \%$ to $21.8 \%$ (HR $0.8,95 \%$ CI 0.73 to $0.87, \mathrm{p}>0.001$ ), death from cardiovascular causes $16.5 \%$ to $13.3 \%$ (HR $0.8,95 \%$ CI 0.71 to $0.89, \mathrm{p}<0.001$ ) and crucially, all-cause mortality from $19.8 \%$ to $17 \%(\mathrm{HR} \quad 0.84,95 \%$ CI 0.76 to $0.93, \mathrm{p}<0.001)$. Importantly, adverse effects were also closely examined. Of note, during the 'run-in' period, $12 \%$ of the ARNI arm withdrew due to adverse events particularly cough, hyperkalaemia, renal dysfunction or symptomatic hypotension although, overall more 'run-in' withdrawals were seen in the enalapril arm. In the main study, sacubitril-valsartan caused significantly more symptomatic hypotension but significantly less hyperkalaemia, cough and renal impairment than enalapril. Although, a non-significant increase in the incidence of angiooedema was seen in the ARNI arm (19 events vs 10 events, $p=0.13$ ), there were no reports of airway compromise in the study as a whole. ${ }^{7}$

In summary, the emergence of ARNIs is a pivotal development in the management of systolic heart failure. In direct comparison to ACE inhibitors, ARNIs demonstrate a significant benefit in mortality, morbidity and hospitalisation rates. This is impressive in the context of patients already optimised with BB, MRAs and device therapy that confer significant benefits of their own. The undeniable fact is that switching patients from the established gold standard of ACE inhibitors to ARNIs will significantly improve morbidity and mortality in patients with systolic heart failure; this is the first new class of agent in antiheart failure therapy since the emergence of BBs 15 years ago. Consequently, ARNIs are likely to precipitate a paradigm shift in the management of heart failure.

ARNI have recently been incorporated into guidance documents. In the UK, the National Institute for Health and Care Excellence recommend sacubitril-valsartan in patients with symptomatic chronic heart failure with $\mathrm{EF}<35 \%$ and who are already taking stable doses of ACE inhibitors or ARBs. It is recommended that the novel therapy should only be initiated by heart failure specialists with access to a multidisciplinary heart failure team. Meanwhile, in the recently updated European Society of 
Cardiology guidelines for the management of heart failure, sacubitril-valsartan receives a class IB recommendation in patients with an $\mathrm{EF}<35 \%$ and elevated NPs (BNP $\geq 150 \mathrm{pg} / \mathrm{mL}$ or plasma $\mathrm{N}$-terminal pro B-type natriuretic peptide (NT-proBNP) $\geq 600 \mathrm{pg} / \mathrm{mL}$, unless there has been a heart failure-related admission in the previous 12 months, when the cut-offs are BNP $\geq 100 \mathrm{pg} / \mathrm{mL}$ or NT-proBNP $\geq 400 \mathrm{pg} / \mathrm{mL}$ ), which remain symptomatic despite an ACE inhibitor, $\mathrm{BB}$ and MRA at the highest tolerated dose. 3536

Sacubitril-valsartan is available in three doses $26 / 24 \mathrm{mg}, 51 /$ $49 \mathrm{mg}$ or $103 / 97 \mathrm{mg}$ twice daily. A starting dose of $26 / 24 \mathrm{mg}$ twice daily is appropriate when the ARNI is replacing a low-dose ACE inhibitor or ARB or when initial systolic blood pressure is $<110 \mathrm{~mm} \mathrm{Hg}$, this should be increased every 34 weeks as tolerated; $51 / 49 \mathrm{mg}$ twice daily is recommended in those who are already stabilised on an ACE inhibitor or ARB, and this should be increased after 2-4 weeks as tolerated. A lower starting dose of $26 / 24 \mathrm{mg}$ is necessary in moderate hepatic impairment (Child-Pugh B classification) or severe renal impairment (estimated glomerular filtration rate $<30 \mathrm{~mL} / \mathrm{min} /$ $1.73 \mathrm{~m}^{2}$ ). In all patients the dose should be increased, as tolerated, at the intervals stated above to a maximum dose of 103/ $97 \mathrm{mg}$ twice daily. Sacubitril-valsartan is contraindicated in severe hepatic impairment, previous angiooedema with an ACE inhibitor/ARB, pregnancy, breastfeeding, a systolic blood pressure of $<100 \mathrm{~mm} \mathrm{Hg}$ and concomitant use of aliskiren in patients with diabetes.

Critically, sacubitril-valsartan should not be administered together with an ACE inhibitor or an ARB. To minimise the risk of angiooedema inferred by simultaneous ACE and neprilysin inhibition, sacubitril-valsartan should only be commenced after a 36-hour period free from administration of ACE inhibitors. Patients should be warned of commonly occurring side effects that include nausea, diahorrea, gastritis, anaemia, hypoglycaemia, hypokalaemia and vertigo. ${ }^{18} 35$

\section{ARE WE MAKING THE MOST OF THE EVIDENCE BASE?}

A central tenet of all the above trials is that the active agent is up-titrated to the maximum tolerated dose. Several studies discussed above highlight the importance of maximal dose titration of ACE inhibitors and ARBs, particularly with regard to effects on mortality and hospitalisation. Despite the overwhelming evidence base, there is a substantial body of evidence indicating that in current clinical practice prognostic antiheart failure therapies are underutilised and suboptimally titrated. ${ }^{16} \quad 17 \quad 28$ Therefore, it is as important to ensure that patients with heart failure receive the available evidence-based treatments at optimal doses, as it is to adopt new advances in disease management, which are also likely to require careful optimisation.

\section{CONCLUSION}

Since the 1980s, heart failure management has changed dramatically. There has been a stepwise progression in evidence-based agents, many of which act via the RAAS, which have transformed the prognosis and morbidity in patients with heart failure. ARNIs are the latest development in this chain and represent the first new pharmacological strategy in heart failure since the emergence of BBs. It is poignant therefore, at this pivotal moment in time, to reflect on the progress made thus far before looking forwards to the next step. In particular, it is of concern that there is a substantial body of evidence arguing that as clinicians we are not currently making the most of the treatments already available in the antiheart failure armament. Even in the presence of such a robust evidence base, it is clear that many patients are either, not on the recommended agents, or more commonly, not on the maximal tolerated dose. Therefore, it is our responsibility as clinicians to critically evaluate new evidence and adopt appropriate new therapies, and also to ensure

\section{Main messages}

- Heart failure is one of the major public health challenges facing the Western world and carries a significant burden of morbidity and mortality.

- The renin-angiotensin-aldosterone system (RAAS) is central to the pathogenesis of heart failure.

- ACE inhibitors, $\beta$-blockers, angiotensin receptor blockers and mineralocorticoid receptor antagonists provide morbidity and mortality benefits in heart failure by antagonising the RAAS.

- The PARADIGM-HF study demonstrates $20 \%$ morbidity-mortality benefit with sacubitril-valsartan compared with enalapril in patients with New York Heart Association (NYHA) class II-IV heart failure and ejection fraction (EF) $<40 \%$.

- In addition to adopting new agents, it is important to ensure that clinicians optimise existing evidence-based agents to provide patients with maximal benefits.

\section{Current research questions}

- Does sacubitril-valsartan provide any benefit in an elderly population?

- Is sacubitril-valsartan as effective in the African population as it is in the Caucasian population?

- Is sacubitril-valsartan effective in heart failure with preserved $\mathrm{EF}$ ?

\section{Key references}

- Effects of enalapril on mortality in severe congestive heart failure. Results of the Cooperative North Scandinavian Enalapril Survival Study (CONSENSUS). The CONSENSUS Trial Study Group. N Engl J Med 1987;316:1429-35.

- Effect of enalapril on mortality and the development of heart failure in asymptomatic patients with reduced left ventricular ejection fractions. The SOLVD Investigators. $N$ Engl J Med 1992;327:685-91.

- Zannad F, McMurray JJ, Krum H, et al. Eplerenone in patients with systolic heart failure and mild symptoms. $N$ Engl J Med 2011;364:11-21.

- McMurray JJ, Packer M, Desai AS, et al. Angiotensin-neprilysin inhibition versus enalapril in heart failure. N Engl J Med 2014;371:993-1004.

- Ponikowski P, Voors AA, Anker SD, et al. 2016 ESC Guidelines for the diagnosis and treatment of acute and chronic heart failure: The Task Force for the diagnosis and treatment of acute and chronic heart failure of the European Society of Cardiology (ESC)Developed with the special contribution of the Heart Failure Association (HFA) of the ESC. Eur Heart J 2016;37:2129-200. 


\section{Self assessment questions}

1. Which of the following courses of action is recommended in a patient who develops a cough shortly after starting an angiotensin-converting enzyme (ACE) inhibitor?

A. Immediately stop the ACE inhibitor and start an angiotensin receptor blocker (ARB).

B. Look for an alternative cause, if it is a severe cough stop the ACE inhibitor and prove association by re-initiating therapy. If this is a true association start an ARB instead.

C. Continue the ACE inhibitor.

D. Immediately stop the ACE inhibitor and start a mineralocorticoid receptor antagonists (MRA).

E. Look for an alternative cause, if severe stop the ACE inhibitor and prove association by re-initiating therapy.

If this is a true association start an MRA instead.

2. In the context of drug titration for heart failure in the community, what is the shortest recommended interval between dose increases for ACE inhibitors, assuming blood pressure and renal function remain within acceptable limits?
A. Every day
B. Every week
C. Every 2 weeks
D. Every month
E. Every 3 months

3. When is it appropriate to consider the use of a MRAs in a patient with heart failure, assuming renal function and blood pressure are acceptable?

A. As a first-line agent alongside $\beta$-blockers (BBs) and ACE inhibitors in patients with New York Heart Association (NYHA) class II-IV heart failure.

B. In any patient with NYHA class II-IV heart failure when they are intolerant to an ACE inhibitor.

C. In addition to a BB and an ACE inhibitor titrated to maximal tolerated dose, in a patient with NYHA class II-IV heart failure.

D. In addition to a BB and an ACE inhibitor at any dose in a patient with NYHA class II-IV heart failure.

E. In those with NYHA class III-IV heart failure despite a low-dose ACE inhibitor, low-dose BB and diuretics.

4. A patient at your practice is receiving ramipril $5 \mathrm{mg}$ once a day, bisoprolol $2.5 \mathrm{mg}$ once a day and $40 \mathrm{mg}$ of furosemide once a day. At a routine check-up, baseline creatinine has risen from 100 to $176 \mu \mathrm{mol} / \mathrm{L}$ and potassium remains normal at $4.9 \mathrm{mmol} / \mathrm{L}$. What is the correct course of action?

A. Exclude alternative causes, stop the furosemide and ramipril immediately and repeat the blood tests in 2 weeks.

B. Exclude alternative causes, stop the furosemide and repeat the blood tests in 2 weeks.

C. Exclude alternative causes, stop the ramipril and repeat the blood tests in two weeks.

D. Exclude alternative causes, if possible stop nephrotoxic drugs including furosemide and reduce the dose of ramipril to $2.5 \mathrm{mg}$. Repeat the blood tests in 2 weeks.

E. Exclude alternative causes, if possible stop nephrotoxic drugs including furosemide and stop the ramipril. Repeat the blood tests in 2 weeks.
5. Which of the following statements is true regarding the use of $\mathrm{BBs}$ in heart failure?

A. BB should be stopped if the resting heart rate falls below $60 \mathrm{bpm}$.

B. When commencing BB for heart failure, a temporary increase in diuretics may be required.

C. BBs are contraindicated in all patients with chronic obstructive pulmonary disease.

D. In BB-naïve patients, BB should be commenced immediately during an acute heart failure decompensation.

E. In patients established on $\mathrm{BB}$, the $\mathrm{BB}$ should always be discontinued during an acute heart failure decompensation.

that we do not forget the foundations on which novel treatments are developed and continue to maximise the benefits of established therapies.

Contributors $\mathrm{CO}$ wrote the manuscript and designed the figures. PSC designed the structure of the manuscript wrote sections of the manuscript and critically reviewed the manuscript. SMS and SGW provided senior critical review of the manuscript.

Competing interests SGW has received honorarium from Novartis for advisory work.

Provenance and peer review Not commissioned; externally peer reviewed.

\section{REFERENCES}

1 Mosterd A, Hoes AW. Clinical epidemiology of heart failure. Heart 2007:93:1137-46.

2 Mehta PA, Dubrey SW, McIntyre HF, et al. Mode of death in patients with newly diagnosed heart failure in the general population. Eur J Heart Fail 2008; 10:1108-16.

3 Stewart S, Macintyre K, Hole DJ, et al. More 'malignant' than cancer? Five-year survival following a first admission for heart failure. Eur J Heart Fail 2001;3:315-22.

4 Jhund PS, Macintyre K, Simpson CR, et al. Long-term trends in first hospitalization for heart failure and subsequent survival between 1986 and 2003: a population study of 5.1 million people. Circulation 2009:119:515-23.

5 Stewart S, Ekman I, Ekman T, et al. Population impact of heart failure and the most common forms of cancer: a study of 1162309 hospital cases in Sweden (1988 to 2004). Circ Cardiovasc Qual Outcomes 2010;3:573-80.

6 McMurray JJ, Adamopoulos S, Anker SD, et al. ESC Committee for Practice Guidelines. ESC Guidelines for the diagnosis and treatment of acute and chronic heart failure 2012: The Task Force for the Diagnosis and Treatment of Acute and Chronic Heart Failure 2012 of the European Society of Cardiology. Developed in collaboration with the Heart Failure Association (HFA) of the ESC. Eur Heart $J$ 2012;33:1787-847.

7 McMurray JJ, Packer M, Desai AS, et al. Angiotensin-neprilysin inhibition versus enalapril in heart failure. N Engl J Med 2014;371:993-1004.

8 Chaggar PS, Malkin CJ, Shaw SM, et al. Neuroendocrine effects on the heart and targets for therapeutic manipulation in heart failure. Cardiovasc Ther 2009;27:187-93.

9 Effects of enalapril on mortality in severe congestive heart failure. Results of the Cooperative North Scandinavian Enalapril Survival Study (CONSENSUS). The CONSENSUS Trial Study Group. N Engl J Med 1987;316:1429-35.

10 Effect of enalapril on mortality and the development of heart failure in asymptomatic patients with reduced left ventricular ejection fractions. The SOLVD Investigators. N Engl J Med 1992;327:685-91.

11 Effect of enalapril on survival in patients with reduced left ventricular ejection fractions and congestive heart failure. The SOLVD Investigators. N Engl J Med 1991;325:293-302.

12 Pfeffer MA. The Survival and Ventricular Enlargement (SAVE) study: rationale and perspective. Herz 1993;18(Suppl 1):430-5.

13 Effect of ramipril on mortality and morbidity of survivors of acute myocardial infarction with clinical evidence of heart failure. The Acute Infarction Ramipril Efficacy (AIRE) Study Investigators. Lancet 1993;342:821-8. 
14 Køber L, Torp-Pedersen C, Carlsen JE, et al. A clinical trial of the angiotensin-converting-enzyme inhibitor trandolapril in patients with left ventricular dysfunction after myocardial infarction. Trandolapril Cardiac Evaluation (TRACE) Study Group. N Engl J Med 1995;333:1670-6.

15 Flather MD, Yusuf S, Køber L, et al. Long-term ACE-inhibitor therapy in patients with heart failure or left-ventricular dysfunction: a systematic overview of data from individual patients. ACE-Inhibitor Myocardial Infarction Collaborative Group. Lancet 2000;355:1575-81.

16 Packer M, Poole-Wilson PA, Armstrong PW, et al. Comparative effects of low and high doses of the angiotensin-converting enzyme inhibitor, lisinopril, on morbidity and mortality in chronic heart failure. ATLAS Study Group. Circulation 1999:100:2312-18.

17 McMurray J, Cohen-Solal A, Dietz R, et al. Practical recommendations for the use of ACE inhibitors, beta-blockers, aldosterone antagonists and angiotensin receptor blockers in heart failure: putting guidelines into practice. Eur I Heart Fail 2005; 7:710-21.

18 The British National Formulary London: British Medical Association and the British Pharmacological Society. http://www.medicinescomplete.com/

19 Pitt B, Zannad F, Remme WJ, et al. The effect of spironolactone on morbidity and mortality in patients with severe heart failure. Randomized Aldactone Evaluation Study Investigators. N Engl J Med 1999;341:709-17.

20 The Cardiac Insufficiency Bisoprolol Study II (CIBIS-II): a randomised trial. Lancet 1999:353:9-13.

21 Effect of metoprolol CR/XL in chronic heart failure: Metoprolol CR/XL Randomised Intervention Trial in Congestive Heart Failure (MERIT-HF). Lancet 1999;353:2001-7.

22 Wollert KC, Drexler H. Carvedilol prospective randomized cumulative survival (COPERNICUS) trial: carvedilol as The Sun and center of the beta-blocker world? Circulation 2002;106:2164-6.

23 Horiuchi M, Akishita M, Dzau VJ. Recent progress in angiotensin II type 2 receptor research in the cardiovascular system. Hypertension 1999;33:613-21.

24 Petrie MC, Padmanabhan N, McDonald JE, et al. Angiotensin converting enzyme (ACE) and non-ACE dependent angiotensin II generation in resistance arteries from patients with heart failure and coronary heart disease. J Am Coll Cardiol 2001;37:1056-61.

25 Cohn JN, Tognoni G. A randomized trial of the angiotensin-receptor blocker valsartan in chronic heart failure. N Engl I Med 2001;345:1667-75.

26 McMurray JJ, Ostergren J, Swedberg K, et al. Effects of candesartan in patients with chronic heart failure and reduced left-ventricular systolic function taking angiotensin-converting-enzyme inhibitors: the CHARM-Added trial. Lancet 2003:362:767-71.

27 Granger CB, McMurray JJ, Yusuf S, et al. Effects of candesartan in patients with chronic heart failure and reduced left-ventricular systolic function intolerant to angiotensin-converting-enzyme inhibitors: the CHARM-Alternative trial. Lancet 2003;362:772-6.
28 Konstam MA, Neaton JD, Dickstein K, et al. Effects of high-dose versus low-dose losartan on clinical outcomes in patients with heart failure (HEAAL study): a randomised, double-blind trial. Lancet 2009;374:1840-8.

29 Pitt B, Remme W, Zannad F, et al. Eplerenone, a selective aldosterone blocker, in patients with left ventricular dysfunction after myocardial infarction. $N$ Engl I Med 2003;348:1309-21.

30 Zannad F, McMurray JJ, Krum H, et al. Eplerenone in patients with systolic heart failure and mild symptoms. N Engl J Med 2011;364:11-21.

31 Kostis JB, Packer M, Black HR, et al. Omapatrilat and enalapril in patients with hypertension: the Omapatrilat Cardiovascular Treatment vs. Enalapril (OCTAVE) trial. Am J Hypertens 2004;17:103-11.

32 McClean DR, Ikram H, Garlick AH, et al. The clinical, cardiac, renal, arterial and neurohormonal effects of omapatrilat, a vasopeptidase inhibitor, in patients with chronic heart failure. J Am Coll Cardiol 2000;36:479-86.

33 Packer M, Califf RM, Konstam MA, et al. Comparison of omapatrilat and enalapril in patients with chronic heart failure: the Omapatrilat Versus Enalapril Randomized Trial of Utility in Reducing Events (OVERTURE). Circulation 2002;106:920-6.

34 Rouleau JL, Pfeffer MA, Stewart DJ, et al. Comparison of vasopeptidase inhibitor, omapatrilat, and lisinopril on exercise tolerance and morbidity in patients with heart failure: IMPRESS randomised trial. Lancet 2000;356:615-20.

35 Ponikowski P, Voors AA, Anker SD, et al. 2016 ESC Guidelines for the diagnosis and treatment of acute and chronic heart failure: The Task Force for the diagnosis and treatment of acute and chronic heart failure of the European Society of Cardiology (ESC)Developed with the special contribution of the Heart Failure Association (HFA) of the ESC. Eur Heart J 2016;37:2129-200.

36 National Institute for Health and Care Excellence. Sacubitril valsartan for treating symptomatic chronic heart failure with reduced ejection fraction, Technology appraisal guidance. 2016. https://www.nice.org.uk/guidance/ta388/chapter/ 1-Recommendations

\section{Answers}

1. (B)

2. (C)

3. (C)

4. (D)

5. (B) 